\title{
Comfortable bodies: sedentary affects
}

\section{David Bissell}

School of Environment and Technology, University of Brighton, Lewes Road, Brighton BN2 4GJ, England; e-mail:d.j.bissell@brighton.ac.uk

Received 6 December 2006; in revised form 8 February 2007; published online 5 October 2007

\begin{abstract}
Whilst to be comfortable is often equated with conservatism and complacency, this paper considers the various and often complex configurations of comfort as a desirable corporeal sensibility. Subsequently, this paper considers what corporeal comfort as an affective sensibility is and can do to theorisations of the sedentary body. The sensibility of corporeal comfort induced through the relationality between bodies and proximate objects is explored to trace through some of the affectual circulations that flow through the sedentary body. With this in mind, forms of subjectivity engendered through the fragility of comfort are at once both active and performed, and folded through the inactive susceptibilities that are beyond activity. Drawing on such an immanent materialism enables us to take more seriously these susceptibilities of the sedentary body and the new moments and spatialities that emerge.
\end{abstract}

\section{Introduction}

For edgy social scientists, 'comfort' is a rather conservative word. To remain within our 'comfort zone' is something that we are led to believe will at best impede our progress and at worst suffocate our creativity, stifle our development, and prevent new avenues from being opened up. To draw on slightly hackneyed business rhetoric, to act outside one's comfort zone, to think 'outside the box', is a highly desirable and necessary hallmark of 'independent and self-motivated' individuals (Chappell, 2006, page 26). It indicates a willingness to be productive, characteristic of Western individualism, not to mention the aesthetico-political impulses of the avant-garde. To remain comfortable in this situation is negative and equates to complacency and a lack of sustained effort: a highly undesirable sensibility. Yet, the situation becomes more complex when, at the same time, to be comfortable may be a highly desirable sensation. The feeling of comfort may be extremely beneficial, a sensation through which an individual may derive a sense of security. Individuals may remain within their comfort zone precisely because it is a pleasant feeling. Conversely, to be uncomfortable is regarded as a highly undesirable sensibility and something that should be minimised at all costs. This paradox is made increasingly complex when different forms of comfort are considered. To be uncomfortable in an undesirable social situation may be, on the face of it, different to the discomfort experienced through a pain in the head. Nevertheless, whilst these two examples appear disparate, the sensations of both are felt through the body: the body is at the nexus of these sensibilities. Comfort is, therefore, a highly complex sensibility and one that requires sustained attention to the nuances therein. Through this paper I would like to focus on corporeal comfort as a complex bodily sensibility. I want to consider what comfort is and how comfort works to affect bodies in multiple and heterogenous ways. While introducing and acknowledging this complexity, I focus on one particular aspect of bodily comfort that will allow an exploration of a particular corporeal configuration. Through this piece, I explore sitting as a bodily configuration where a desirable sensibility of comfort can potentially be attained. Sitting provides an ideal framework through which to explore the nuances of comfort, how it can be achieved, and, conversely, how it can subside. 
In considering comfort, this paper aims to open up lines of investigation into two main areas of thought. The first analytical trope that this paper seeks to address is that of the dialectic of mobility and immobility. Through research on mobilities of bodies and objects, embodied subjectivity is increasingly conceptualised within a world of increasing flows, in terms of both quantity and velocity (Vidler, 2000; Virilio, 1997). Such studies have often been framed within the meta-ideology of degrees of freedom where mobility is positively related to agency as an outcome of various power relations. Despite notable exceptions (for example, Spark, 2006), slower bodies or stilled bodies are depicted as having less agency and are therefore subsumed within the projects, more often than not, of more agile agentive bodies (Adey, 2004). Conversely, stilled bodies have also been invoked as an example of a transgressive performance to impede various forms of movement. Examples here could include acts of protests or sit-ins or various acts of slowing as resistance to a perceived frantic world of acceleration (Bell and Leong, 1998; Parkins, 2004). However, much recent work on mobilities within the social sciences has focused on the relative mobilities of bodies and objects, of stillness and movement as not oppositional (Cresswell, 2001; Cresswell and Verstraete, 2003). Indeed, Cresswell's (2003; 2006) work has consistently critiqued issues of nomadism and unrestrained mobility, focusing instead on the contingent relationalities between different forms of movement and stillness. Similarly, Adey (2007) has described how immobilities and corporeal stillness are at the heart of and fundamental to the machinic assemblage of the airport as an example of a place traditionally associated with flow and fluidity. This maturity in mobilities research is beginning to take seriously the relationality between stillness and movement and their mutual constitution. A focus on comfort through sitting enables us to open a vein within this literature that will permit a more nuanced interrogation of the implications and the dynamics of the phenomenon and their implication in the constitution of sedentary bodies. Whilst this 'new mobilities' literature (Hannam et al, 2006) is critical of sedentarism per se - the fixed, the undialectical, of being over becoming - the question this piece sets out to interrogate is whether these critiqued ontologies are an inevitable part of a sedentary account. Maintaining a corporeal focus enables us to consider how periods of corporeal sedentarism are experienced through the body. In turn, this focus on bodily capacities will assist in moving away from these oft-critiqued aspects of sedentarism by thinking through how sedentary bodies are still implicated in the dialectic of movement and stillness.

The second analytical trope which this study draws on is the emerging commitment to affectual intensity within the social sciences. Within geography, such a commitment to affective modalities is highlighted through work on performativity and agentive corporeal potentialities (see Dewsbury et al, 2002; Gregson and Rose, 2000; Latham and Conradson, 2003; Nash, 2000). Drawing on these interlinked rationales of embodiment and performativity, the majority of studies about corporeal experience have focused and privileged the active body. Recent examples of such energetic sensibilities include walking (Morris, 2004; Solnit, 2000), cycling (Spinney, 2006), playing (Harker, 2005), caravanning (Crouch, 2001), and photographing (Crang, 1997; Larsen, 2005) to list a few. These accounts that take seriously the transhuman entities that fold through and circulate through and between bodies have touched on a range of affective sensibilities that has become an integral part of thinking through everyday landscapes. Affects such as anger and fear through to happiness and joy are increasingly being recognised as central to the comprehension of subjectivity. Whilst there is no fixed definition of affect, all definitions of affect tend to "depend on a sense of push in the world" (Thrift, 2004, page 64). Given this context, those who have narrated some of the various effects of affect have tended to focus on quite intense affectual processes 
and events, producing accounts of the qualitative effect of these intensities, through their amplification (Thrift, 2000) and dampening (Anderson, 2004). And, yet, we should keep in mind that intensity in this respect can and should be considered as a sliding scale (see Ophir, 2005) with less overtly 'intense' intensities being of no less importance to everyday conduct and requiring no less skilled composition in their maintenance. It is precisely these differentiations of intensity that I want to think through when considering how comfort is enacted through the body (see also McCormack, 2002; Wylie, 2005). Whilst bodies may be physically still, the body may not cease to be moved, affectually. To consider the affective capacities of the physically immobile body will assist in exploring the types of comfort experienced by sedentary bodies.

In this case, both speed and slowness emerge as transversal qualities of bodyobject assemblages. These apprehensions of im/mobility and affective intensity assist opening up possible ways of thinking through how comfort as a corporeal sensibility is experienced by sedentary bodies. Such an intervention will assist in expanding the epistemological remit of the everyday (Siegworth, 2000) and, as such, will help to open up new spaces and vocabularies with which subjectivity is negotiated. This intervention is important since much of our everyday routine is spent in a relatively inert and sedentary configuration whether we are sitting on a bus, train, in a car, or in a chair, sitting at a desk. Indeed, we seem to spend so much time being held and contained that the very familiarity of this corporeal practice seems to have obscured it. Ontologically, these events of bodily stasis that I want to address and explore are not subsumed beneath or relative to faster rhythms but instead a specific kind of relation-to-the-world that transcends and folds through this dialecticism of (im)mobility (Bissell, 2007). So how best to think through comfort? Through section 2, this paper introduces comfort as an affective complex that is felt through the physically sedentary body. This requires thinking through the dualistic nature of comfort as both objective and aesthetic before proceeding to think through the term as an affective transhuman resonance. Section 3 establishes the chair as the nexus of an assemblage comprising body and proximate environment. This assemblage provides the necessary lens to think through the implications of comfort. Section 4 explores comfort as a strategy through the various hybrid relations enacted within this assemblage: through chair and body. Section 5 proceeds to consider what is beyond comfort: when comfort as a nonintense sensation becomes more intense. Whilst the spatialities of these intensities are not the central tropes under investigation, such a theme nevertheless illuminates how comfort and discomfort can be techniques and technologies of spatial ordering and differentiation. Through this investigation, comfort is refined as a complex affective mode of being and a fragmentary becoming that vacillates between action and inaction, intensity and nonintensity: comfort as both agentive and more-than-agentive.

\section{Defining comfort}

While 'comfort' and 'being comfortable' are integral aspects of corporeal experience there is a lack of consensus on what comfort actually is. Comfort is not new to sociogeographical literature and its usage spans a wide variety of disparate fields of study. Similar to 'hope' (Anderson, 2006) and 'joy' (Bennett, 2001), it can potentially have a positive and desirable resonance. Indeed, other literatures, particularly within medical anthropology, describe comfort as a basic and fundamental human need (Malinowski and Stamler, 2002; Tutton and Seers, 2003). Studies investigating the politics of belonging frequently invoke comfort as a qualitative index to explore subjectivity - that is, comfort with physical appearance or sexuality (Holliday, 1999). Through cultural geography, the sensibility of comfort has frequently taken on gendered connotations to 
describe a certain often-feminine spatiality of the home and been related to warmth and domesticity (Morin et al, 2001; Yu, 2003). Similarly, postcolonial literature has sought to excavate historical landscapes of comfort within former colonies (Duncan, 1990; Duncan and Lambert, 2004). In addition, much recent work that deals explicitly with comfort focuses on the various renderings of personal thermal comfort with particular reference to the development of new environment-regulating technologies within the wider concerns for climatic change (Chappells and Shove, 2005; Shove, 2003a; 2003b). This emergent body of literature demonstrates how comfort as a term is a highly diversified and often contentious issue and it is extremely difficult to arrive at a consensual description. Comfort is clearly multidimensional, played out across various axis of analysis. I want to suggest three specific definitions of comfort that build on each other: first, as an objective capacity; second, as an aesthetic sensibility; and third, as an affective resonance.

Firstly, comfort is often anticipated as an objective capacity. The heritage of this particular rendering can be traced through the history of objects and design. Prior to the 18th century, comfort "primarily meant moral, emotional and political support in difficult circumstances" (Crowley, 2003, page 4). Gradually, its definition has shifted to refer to commodities and objects of luxury. This shift was engendered partly by the consumer revolution during the 18th century. Such a definition premised comfort as not a sensibility felt through the body but an almost wholly visual sensibility. Indeed, during the 18th century, as Crowley comments with reference to furniture, "seating was a visual phenomena... [where] furnishings represented taste" (2003, page 12). This, of course, is not identical to physical corporeal comfort, the imperative of which emerged only during the early 19th century where comfort increasingly stood for desirable physical circumstances. Indeed, as Crowley posits, "by the turn of the nineteenth century, Anglo-American social thought had naturalised the desire of physical comfort [that] had become a set of expectations, physical designs and personal imperatives" (2003, pages $42-43$ ). Comfort as a specific feeling in these examples is a socially constructed and engineered attribute of an object. Here, there is an objective way of being comfortable in a seat and consequently a prescribed posture for sitting comfortably. This could be described as biomechanical comfort, which is frequently used as a distinguisher on a continuous scale when describing the relations between specific objects such that 'this is more comfortable than that'. Crucially, comfort in this sense is objectified and made tangible and connoted with an object: as a particular attribute of the object itself.

Secondly, comfort has been characterised as an aesthetic sensibility, a sensation of being-at-one with the immediate environment that might include the presence of others, together with a combination of memory and anticipation of specific events (Helander and Zhang, 1997). Invocations of comfort as an aesthetic sensibility often seem to be at the forefront of both contemporary design and marketing. Indeed, part of the remit of architects is to design and create environments that have the capacity to affect and induce a sensation of comfort (de Botton, 2006; Evans, 1980; Gowans, 1989). An aesthetic definition of comfort builds on the objective, in that a particular object can be made to be comfortable, but considers more seriously the relationality of the object and particular user. Comfort in this sense could be defined as an "improvement on the outside weather", for example (Cooper, 1998, page 89). Similarly, town planners design places that users feel comfortable in (Gómez et al, 2001; Sarkar, 2003). This definition tends towards considering the affective potentiality of comfort as a quality not that resides solely in an object, but that is brought into being through bodies. This rendering therefore steps beyond the 
biomechanical by considering the semiotics of comfort as generative of particular aesthetic meanings.

Thirdly, if we think through comfort as a specific affective resonance, then comfort as a sensibility is not captured, enclosed, and objectified through specific technologies or objects but can circulate between and through both objects and bodies. Such a circulation of comfort as an affective medium is demonstrated well through the marketing campaigns of early motion picture houses where it was the sensations of the internal environment of the theatre itself that were marketed over the content of the film showing (Cooper, 1998). Through the affective lexicon of comfort, marketing strategies were designed to emphasise the appeal of the theatre itself. The internal environment was engineered principally through air conditioning that "removed the temper from temperature" (page 93). Where such historical accounts of comfort were principally focused on circulating the thermal comfort of the environment, accounts of contemporary cinemagoers also frequently invoke comfort as a motivating factor for choosing a particular cinema (Hubbard, 2003). In a similar vein, many travel companies promote an anticipatory sense of comfort through marketing campaigns and, in doing so, enact a specific discourse of what it is to be comfortable. Rather than solely the thermal comfort of an environment, transport companies such as Eurostar, Great North Eastern Railway, and British Airways enact a more complex and multifarious definition of comfort that emerges from a number of other sensibilities such as quietness, solitude, relaxation, slowness, and beauty. Promotional material for first class travel emphasises the potential for comfort through relaxation, stating "Our trains and First Class Lounges provide a calm stress free environment where you can work peacefully or just relax .... At the end of the day unwind with a drink - or simply relax as time goes by" (Virgin Trains, 2005a). Similarly, Virgin Trains assures potential customers that "Travelling by train is one of the easiest ways to travel ... you just sit back and spend the time as you will until gently delivered to your destination" (2005b, emphasis added). The lexicon of gentleness again promises that bodies will not be subject to more agitated forms of movement that could potentially disrupt these desirable comfortable sensibilities. Where discourses of comfort are engineered through the marketing of long-distance operators, such discourses are central to those providing overnight services where pleasant disengagements in the form of sleep are desired by all bodies. The strap-lines "a dream of a journey" and "comfort as light as a feather" reinforce to passengers that the experience of travelling by sleeper train will ultimately induce pleasant forms of comfort, chiefly a good night's sleep (City Night Line, 2005).

In this third definition, we move away from comfort as objectified or as intentional and instead present comfort as a complex set of affective resonances circulated through a variety of tactile, visual, and audio media. Comfort is no longer solely an attribute of an object but more a set of anticipatory affective resonances where the body has the capacity to anticipate and fold through and into the physical sensation of the engineered environment promoted. These anticipatory resonances demonstrate how such marketing campaigns are complex in that they seek to sell not only a comfortable chair or a comfortable, aesthetically seductive object, but also a pleasant corporeal experience. These complex and often successful engineerings ensure that comfort can be partially known and therefore sold and circulated. Yet, contra Christiansen (1997) and Greil (1997), comfort is not wholly predetermined and is reliant on bodies themselves to facilitate this circulation. 


\section{The chair}

Chairs occupy an intimate place in our lives. Through the remainder of this paper, I want to hold onto and develop the complex, shifting, and incomplete rendering of comfort through an investigation of a particular body-object configuration. In order to appreciate the relationality between sedentary body and proximate environment, I want to consider the practical minutiae of corporeal comfort through the specific technology of the chair. There are many reasons for engaging with this specific object. Sedentary bodies invariably spend much time seated. Certain types of office-based work are frequently undertaken whilst sitting in a chair, and the rising number of people travelling over longer distances more frequently, in cars, trains, and planes, also necessitates that a greater proportion of everyday life is experienced from a seated position. For all the attention that walking has and continues to receive, and despite the reflexive awareness of the problematic prioritisation of this practice (Wylie, 2005), it is the case that the chair is frequently the site of the practice of everyday life. The chair is routinely at the nexus of how feelings and affects of comfort are weaved through, comprehended, and evaluated. Much occupational health literature follows a rather determinist line positing that, by shifting certain objective and uniform physical variables, there is an optimum way of sitting where comfort can be achieved. However, comfort as a corporeal feeling clearly depends on the capabilities and capacities of individual bodies themselves (Stone, 1995). The act of being sedentary through sitting has a considerable biomedical and literary history that has often touched on the notion of affect through comfort. Since the anatomical formation of the human body is designed for movement and not for sitting, sitting could be characterised as an unnatural form of corporeality. As Cranz reminds us, how we hold our bodies in a chair should be acknowledged in a cultural context in that "our chair habit was created, modified and nurtured, informed and democratised in response to socialnot genetic, anatomic or ... physiological forces" (2000, page 30). Equally, therefore, chairs have a long history, as symbolic regulators to demarcate status differences and they pervade symbolic life as metaphors for position: through university 'chairs' and 'chairperson', for example. Throughout the history of chairs, designers have constructed relative degrees of comfort and aesthetic superiority to their designs, juggling both status and comfort, often depending on the moral philosophy of the designer (Cranz, 2000). Cranz argues that chairs today are embedded in a complex network of gendered power relations where chairs, particularly in the domestic realm, continue to reflect gender distinctions. Women as traditional holders of the domestic domain select more masculine styles of chair for the more public rooms of the house. Indeed, Cranz argues that women designers have been interested less in the chair as an agent of hierarchy and power and more as a medium for relatedness and physical ease.

Considerably less attention has been devoted to investigating some of the various social practices of sitting with the exception of where other activities are undertaken whilst sitting: for example, eating (Valentine, 1999) or watching a film (Hubbard, 2003). Again, it is the active corporeal processes that continue to attract academic attention. However, there have been a small number of studies which have investigated the corporeal practice of sitting in a chair outside the home. Such iconographic symbolism is arguably quintessentially American as both Harris (1997) and Buchino (2003) discuss through their studies of 'porching'. Sitting has also been studied as a form of resistive practice for creating control as McColgan (2005) asserts with reference to mental health settings. Additionally, sitting has been noted as a practice for corporeal wellbeing through forms of meditation and silence (Schrauwers, 2001). Indeed, sitting as corporeal practice specifically without movement forms the basis of the Buddhist practice of Shikantaza, where the stillness of the body induces a sense of calm and 
well-being (Loori, 2002). Whilst these studies provide some useful insights into the nature of what it may be to sit, they lack a sense of the affective synergy that moves between bodies and chairs. Though they may casually invoke or allude to a specific affective relationality, they fail to address affect and sensation head-on as important objects of study in themselves. Put simply, these bodies are oppositional: either in movement or still-nomadic or sedentary. A more responsive notion of comfort that appreciates both the corporeal stillness of the body and the movement of affect can be drawn out by attending to the sensibilities involved in this relationality. In this way, the chair emerges as a specific and known place as Tuan suggests:

"My favourite rocking chair, wedged between the fireplace and the curtained window, is my special place within the house. It has a specific location, it has special meaning to me.... The rocking chair within the home [is] a recognisable place.... The sentiment is there, and we learn how strong it is when these small foci of our world are disturbed or threatened. But the sentiment does not often rise to the surface of our consciousness. The old armchair and a quite ordinary bed are not aesthetic objects that require our admiration and critical judgement. They are known, intimately, through the more passive modes of experience" (1975, pages 155-156).

Whilst bodies are often engaged in other forms of activity whilst sitting, such as typing, talking, listening, eating, driving, waiting (for a more detailed account, see Bissell, 2007), and reading to list but a few, the physical configuration of sitting should not be devalued as a subordinate state. It is, rather, or at least more often than not, the condition of possibility for the conduct and continuation of these tasks. Thus, although active consciousness may often be directed towards the specific task in hand, I do not want to apprehend sitting as something done 'in order to'. Rather, I would suggest that corporeal comfort is precisely the background condition for the formation of such intentions. Are you sitting comfortably? Then you can begin.

\section{Comfort strategies}

I now want to consider more closely the corporeal experience of comfort as an affective relation between body and chair. Through a relational ontology that transcends the dualisms of objective or aesthetic, corporeal comfort is an embodied contingency forged between the body and the proximate environment. Through this rendering, the chair acts on and transforms the body and, conversely, the body acts on and transforms the chair. If comfort does not reside in any particular object but is an affective sensibility that is created then bodies must have to work with chairs to effect this sensation. Put simply, it perhaps takes bodily effort to be physically comfortable: the body - chair assemblage has to be negotiated. Here, I want to consider some of the various corporeal strategies involved in effecting comfort. The quotidian practice of 'getting comfortable' in a seat, for example, is a familiar notion but if developed further exemplifies this corporeal effort required to effect a certain affective sensibility. The effort of getting comfortable tends to suggest that it is an active state which precedes a state of comfort, a necessary and inevitable precursor. Indeed, this notion of getting comfortable, of becoming comforted, is often vocalised in a linear sense. However, in practice, such a chronology to comfort is usually far from the case and instead shifts and slides through time where the body ebbs and flows in and out of feeling comfortable. Bodies can perform a series of gestural sequences in order to achieve an optimal sensation of comfort. Instead of thinking through comfort as a mutual and takenfor-granted embedding of body and environment, it is "more a double movement of contraction and dilation in which a certain corporeal sensibility twists forth in ache, ennui and enervation" (Wylie, 2005, page 242). Bodies may develop a range of gestural strategies and tactics to achieve such corporeal sensibilities. These could include how 
the legs are held in space, and whether they are crossed, spread out, bent at the knee with feet on the floor. The whole body is enlisted in the quest for a comfortable sensation: from the shape of the back against the chair, to the curvature of the neck, to how the arms are held. Therefore, such a desirable sensation when in a sedentary position such as seated arguably does take corporeal effort. This is perhaps surprising since comfort is assumed to be a relaxed sensibility and therefore unpressurised and somehow effortless.

There is a certain caveat that must be momentarily broached. Specifically, it seems that the definition of comfort here is presented as a uniform sensation experienced and desired by all sedentary bodies. Far from appealing to some form of universalism, I should stress that comfort as an affective sensibility is enacted in a wholly multidimensional way. Many commentators would argue that corporeal comfort is folded through a whole variety of other performances and corporeal commitments, and therefore comfort should be conceptualised as a variegated affectual complex. Indeed, when sitting in a chair, there is an assumption that bodies will inevitably attempt to get comfortable, to induce a pleasurable synergy between chair and body. When we sit in a chair, we want to feel a pleasant sensation of rest and ease that could be described through the lexicon of comfort. Even when the body is in a relatively inert and sedentary state, some would argue that, from a performative perspective, the body, far from bowing out of some kind of performative register, maintains and regulates a seated performance that enacts a specific corporeal identity. These performances necessarily alter and reshape this notion of comfort, broadening it such that corporeal comfort folds through the proximate environment, including the presence of other people. Indeed, sitting in a seat in the presence of others is an occasion for the observation, classification, and judgment of bodies (Foucault, 1991). To draw on Butler's (1997) politics of performative resignification, such performative gestures could reinforce a certain style of enacting gender or sexuality. Being comfortable is therefore implicated and folded through the discursive constitution of subjectivities. Youdell (2005, page 255) demonstrates through extensive fieldwork within the framework of a secondary school how "the most mundane bodily practice - sitting - is constitutive of multiple identities". This practice of being sedentary and being without movement still has the capacity to "cite and inscribe multiple discourses of the sexed body". These bodily practices are the practices of the performative habitus (Butler, 1997), at once formed by and formative of discourses of bodily femininity and masculinity. When seated, this could include enacting modes of corporeal expansion such as through spreading the legs or sitting with the legs apart as a performance of heteromasculinity. Indeed, Youdell found that females' sitting positions inscribed a "discursively constituted heterosexual femininity in which the feminine body is small, tidy, restrained and deferential" (2005, page 255). Comfort in this regard is folded through performed identity and bound up with signification and the continued viability of the subject through bodily practices "which are necessarily repetitious and citational" (page 256). Such performances echo Mauss's (1973) notion of 'body techniques' where the materiality of various gestures varies both historically and culturally. However, through Youdell's example, practices of sitting are equal to 'being' rather than actively 'doing'. I would argue that, rather than inert, the seated body is constantly refiguring and becoming refigured through the cultivation of a sensibility of comfort. Such performative gestures are not antithetical to the affective nature of a sedentary comfort though. Comfort as a variegated affective complex moves and folds through these performances, thus continually refiguring the nature of the sedentary body. 
However, there seems to be a problem in this rather unidirectional rendering of affect. Specifically, it presumes that such an affective sensibility recreates the notion of the body as the active and agentive subject. Through a construction of a sedentary sensibility, we must equally consider how objects mediate these more-than-representational sensations. Comfort as an affective relationality between bodies and objects must consider the way in which the chair also acts on the body, thus mediating the nature of affect experienced through the body. To focus on the active seated body neglects and obscures some of the other relationalities that form between the sedentary body and the chair. Such lines of argument can be exemplified through a number of quotidian situations drawn from the corporeal travelling experience where different situations at various stages of a journey are engineered to be more or less comfortable. Since comfort as an affective sensation has thus far been conceptualised on a continuous scale, it could be argued that Crowley's (1999) assertion, where historically comfort designated status, is still evident through the retention of different standards of class on board planes and trains according to ability to pay. The primary difference between standard class and first class is that the latter has seats that are engineered to promote increased sensations of comfort. These seats are wider and have greater legroom, permitting the body to spread out and they facilitate a wider range of possible performances through increased space allowance. Additionally, first class seats tend to be made from softer materials that also may promote enhanced sensations of corporeal comfort. The various surfaces and material dimensions therefore set up a different relationality between the body and the chair. The larger chairs in first class often have armrests and headrests and are made out of more luxurious materials that effectively enclose the body. They hug and reassure the body and are designed to induce a particular set of affective relations, chiefly a sense of relaxation. In stark contrast, other seats in the travelling environment, such as benches at stations, foster and are designed to induce a range of very different affective resonances that are far from comfortable. Notwithstanding their need for physical durability in often-inhospitable environments, these seats are typically constructed from materials such as metal that are hard and cold and therefore less comfortable for the body. In addition to the absence of armrests, these seats tend to have a poor back support or none at all and, as such, do not promote an affective bodily comfort. Bodies in transient places are engineered to be upright and erect. The emphasis on these transient places of passage does not seem to be placed on corporeal comfort. Indeed, the shape, material, and design of seats in these places suggest that the body-in-waiting at a station must be alert and attentive. Albeit in a different theoretical and political register, such a thesis echoes Davis's (1998) writings on Los Angeles, where particular built forms, particularly at street level, are engineered to be either more comfortable or less comfortable through municipal policy that serves to perpetuate divisions of class and race.

In these cases, the chair itself directly influences the type of affective sensibility felt through the body by mediating performances: the chair as an everyday technology shapes how we use our bodies (Tenner, 2003). Through their design, chairs are engineered to facilitate and impede different sedentary performances. Furthermore, the large body of work on the aesthetics of chair design both historically (de Dampierre, 2006) and more contemporarily (Byars, 2006; Fiell and Fiell, 2005; Meadmore, 1997) reveals a complex genealogy of the changing relationalities between comfort, practicality, aesthetics, sitting strategies, and corporeal sensation. Nevertheless, whilst the role of chairs is arguably heterogeneous and distributed, the potential range of possible performances is rather limiting in that chairs on trains and planes, at stations and airports, are designed primarily to temporarily hold the body upright. Other performances such as stretching, sleeping, or even conversing with people sitting behind 
are effectively impeded or rendered less comfortable. To acquiesce in these places actually does take a considerable amount of effort (see Callon and Law, 2005). For example, when sitting in a seat on a train it is often difficult to sleep and therefore strategies may be enlisted and worked at to make the body sleep: to actively cultivate a sensibility of acquiescence. Similarly, chairs at transport terminals, particularly airports, are often designed to impede forms of acquiescent subjectivity where bucket-style seats and high metal armrests engineer such spaces to impede sleeping (McSherry, 2006). To promote a comfortable and relaxed sensibility in places where such affects are impeded, it is often necessary to enlist a range of other objects. For example, travel pillows could be used whist sitting to achieve a comfortable posture for inducing sleep. Similar to Michael's study of walking boots, such objects help to "reshape the affordances of nature by expanding the range of possible actions available to the body" (2000, page 112). The chair mediates interpersonal relations too, rendering some forms of interaction less comfortable than others, and induces different forms of intersubjective sociality. For example, when you are being held in airline-style seats on a plane or train, talking to your neighbour often does not involve eye contact and therefore induces a different form of bodily comfort.

\section{Beyond comfort}

Far from wishing to appeal to a sense of rationalist determinism, these examples provide useful and tangible evidence to describe some of the ways in which the seat as proximate object folds through the body and permits different affects to move through the body-chair assemblage. Nevertheless, they also raise some key questions of how we comprehend comfort as a specific set of affects. Comfort, like affect, has thus far been conceptualised on a sliding scale of differentiation: namely, high or low, intense or nonintense; you can be more or less comfortable. However, what is not so obvious is which end of the scale comfort should be placed on. Put simply, is desirable comfort an intensification of affect or conversely a waning of affect? Could the apotheosis of an affective comfort paradoxically be a deadening of affect, a nonintense sensibility? It would certainly be seductive to agree that this is indeed the case. If comfort as affect is allied with the lexicon of relaxation and restfulness, Harrison's (2008) recent paper points to how a nonagentive subjectivity can effectively bow out of the schema of autoaffective action. This acquiescent sedentary body at rest or pushed further, at sleep, would therefore be the ultimate comfortable body. However, the affect of comfort that this paper has described thus far is also imbued with a sense of corporeal pleasantness: a wholly desirable sensation. Anderson's (2004) insight that the deadening of affect is part of what makes boredom an undesirable experience certainly suggests that comfort, as an affective sensibility, is not equal to the deadening of affect. What seems to make comfort such a desirable affective sensibility to the body is precisely that it is not at either end of the continuum. Comfort does not have to be at the end of this scale: intensity or nonintensity. Optimum comfort as a relaxed, consoling, and reassuring affective sensibility might be best conceived as occupying the middle ground of this continuum. Indeed, it could be this neutrality that makes it so difficult to discern and narrate as a specific mode of feeling (see Barthes, 2005). This neutrality can, of course, be felt and apprehended only in relation to other modes of feeling. Furthermore, whilst corporeal comfort might be a neutral sensibility, the sensation of comfort might also have the capacity to precipitate all kinds of imaginative intensities through daydreaming, for example (see Bachelard, 1987). So what happens when comfort twists forth and ruptures and a new set of affective resonances takes flight? What is beyond comfort on this continuum? 
In tracing through the complex affective relationalities between proximate environment and bodies, I hope to have demonstrated that corporeal comfort as an affective sensibility should not be limited to a purely visual and aesthetic sensibility as postulated through much of the ergonomics literature (for example, Helander and Zhang, 1997). Stilled bodies and inert seats are mutually implicated in the circulation and moving through of various affective resonances. However, we seem to have stalled at an impasse. Comfort seems to be best conceptualised as a potentially neutral sensibility: comfort is not intensity; neither is it the deadening of sensation. What seems to be omitted from much of the literature that discusses corporeal comfort is the temporal sustainability of corporeal comfort. Comfort, far from an inert sensibility, is never stable and the complex of affective sensations associated with being comfortable is always at risk of transformation. Here, I want to move forward to consider the vulnerability of comfort and what comfort is always at risk of moving beyond into.

I have already commented on how environments engineered to circulate differential levels of comfort have differential sensate longevities. To draw on a prosaic example, chairs that are designed to be more comfortable sustain longer periods of comfort than those which are designed for more fleeting engagements such as benches. However, in each of these cases, comfort is an affective complex that is always-already being negotiated and therefore, within it, always contains the potential of slipping beyond comfort or what is pleasurable (see Ophir, 2005). The biomedical literature has traditionally described such a sensation as a temporally discrete polar opposite to comfort: discomfort. Similarly, much of the ergonomics literature describes comfort and discomfort as two qualitatively distinct modes of being (Helander and Zhang, 1997). However, I want to move beyond such essentialist notions of discomfort by considering how discomfort is contained within and is always immanent to comfort. Such a thesis not only has the effect of unsettling and destabilising how comfort is conceptualised but also refigures how we come to know and understand the affective capacities of sedentary bodies. Since discomfort and pain are semantically similar terms, insights into pain provide a useful lens to excavate this beyond of comfort. If comfort is conceived as a potentially neutral sensibility then surely pain should be conceptualised as a pressing affectual corporeal intensity. In the case of sedentary bodies, pain is not some kind of individual interior state (Scarry, 1985) but induced through the relationality between bodies and objects, "a resonance of things as a whole" (Wylie, 2005, page 244). Much that has been written in the social sciences on the affectivity of pain has focused on the experience of temporally sustained or chronic pain (see Hellstrom, 2001; Honkasalo, 2000; 2001; Jackson, 1994; 2005; Miles et al, 2005). However, rather than focusing on chronic pain, here I want to focus on the everyday quotidian moments of transient pain which transcend sedentary bodies.

A heightened attention to temporality is important here in that bodies slide between these affective complexes over time. Whilst the sensation of pain is itself not induced through any auto-affective corporeal agency, bodies may enlist a variety of strategies to overcome such sensations. These strategies restrain comfort and prevent it spilling over and transforming into discomfort and pain. To draw on a further everyday example, when sedentary bodies on board a plane or train experience these slides between comfortable and noncomfortable affective complexes, such agentive strategies that attempt to redress this balance typically involve some degree of corporeal movement. Fidgeting is an often-cited response to bodily discomfort (Cranz, 2000): a choreography of gestures where a changing bodily position redistributes pressure. Indeed much is made of the importance of leaving the seat and walking around together with a series of prescribed exercises at the seat (Torkelson, 1999) to regulate and preserve a sustained sense of corporeal comfort. Therefore, it could be argued that the body is 
never wholly sedentary at the microscale (see Massey, 1993). At this scale, even the stillest body is always to a degree a fluid, moving, shifting configuration. Pushed further, such a thesis problematises this relationship between the sedentary body and the necessity of stillness to effect comfort. Where bodies may be experiencing much corporeal pain, sustained periods of physical movement may actually assist in precipitating increased comfort (McCaffery and Wolff, 1992). Conversely, some of the worst kinds of torture are associated with enforced stillness, such as the confinement of a prison cell.

As previously outlined, bodies necessarily become comfortable. Therefore, bodies must also have the potential to move beyond this comfortable affective complex: to move beyond comfort. As the body moves beyond comfort, a different set of affective sensations may come into circulation such as pain and discomfort. Textualised, these sensations could be leg aches, back pains, or a more general corporeal heaviness. Crucially, for this paper, such sensations are not brought about through auto-affective action. The body does not actively induce these painful sensibilities. Indeed, "the inability to flee or retreat, the being mired in oneself, is the suffering of pain" (Lingis, 1996, page 81). These sensations can emerge through and proceed from the very act and susceptibility of corporeal stillness. A sense of corporeal vulnerability is therefore central to this notion of susceptibility. In this respect, the affective sensibilities of pain are similar to Harrison's (2008) passionate desubjectification and are qualitatively similar to sensations of tiredness and lassitude. As Lingis points out, "to be pained is to feel one's own substance as a passive affliction, in the torment of wanting to escape oneself" (1996, page 85). To be in pain could therefore be conceptualised as a mode of being-in-the-world (Merleau-Ponty, 1962, page 79) or as the condition of the (potential) loss of that world. Through these sensations beyond comfort, the relationality between body and chair is constantly refigured. The chair becomes something other, something different. Rather than a comforting object that caresses, cares for, and hugs the sedentary body, through the affects of pain, the chair becomes an object of harm, distantiated against the body. The trusting relationality nurtured between body and chair falls asunder and "new postures and surfaces materialise and new affectual extensions resonate" (Wylie, 2005, page 244). Whilst this may seem a rather pessimistic evaluation, its fragility demonstrates that comfort in an absolute sense may be rarely if ever achieved. The sustainability and durability of comfort therefore rely on incremental corporeal motion to effect moments of increased comfort. In this light, sitting may result more often in discomfort than comfort.

\section{Conclusion}

To return to the problematic posed at the start: is comfort a desirable sensibility? Through the focus on physical corporeal comfort in this piece, I have argued that to be physically comfortable is indeed a desirable, if sometimes difficult, aspiration. For the seated body, the mobilisation of comfort through the negotiation of the complex relationality between body and chair can potentially produce a set of pleasant affective corporeal sensations. However, whether such renderings of corporeal comfort can be transposed into other registers of everyday life is slightly more problematic. In situations where comfort is perhaps considered a complacent sensibility, uncomfortable corporeal sensations are valued in that they will result in eventual (and usually economic) benefit for the individuals concerned. Such a valorisation of chastity through the deferral of gratification may ultimately be rewarded by enhanced comfort. Yet, in other situations, this valorisation of discomfort could hardly be deemed appropriate or desirable, particularly in the context of physical pain. Such differences not only reveal the complex and contested nature of physical comfort but also raise questions about 
the wider ethicopolitical implications of bodily comfort. Corporeal discomfort may be at the heart of the experience of poor or inhospitable living conditions (see Powell et al, 2001). Although it is clearly no easy task, being able to understand and narrate those physical embodied experiences may be key to helping to alleviate these undesirable sensibilities.

Approaching comfort from the perspective of relatively sedentary corporeal states has opened up the remit for thinking through being still. Where sedentary ways of thinking have previously rendered bodies as undialectical and fixed, crucially this piece has demonstrated that these are not inevitable parts of a sedentary account. In charting some of the complexities of this process, this paper has opened up thinking through the experiences of sedentary bodies in a number of important ways. To take seriously the movements of affect necessitates that sedentary bodies are never still. The inert body is always already experiencing a myriad of affectual complexes and sensations. "These affects are neither mysterious trans-human determinants of our sensibility, nor are they simply vectors of personal psyche, emotion or intention. They produce and circulate within a non-subjective, sometimes intersubjective relational spacing" (Wylie, 2005, page 243). Focusing on comfort as a sensation felt through the body enables us to consider more effectively these shifting affectual dimensions, particularly where comfort ruptures, splinters, and moves beyond what could be deemed a pleasurable sensation. In this way, the physically stilled body remains at the nexus of affective resonances. Indeed, such is the mutual constitution of various movements and stillnesses that these words may be insensitive at transmitting the nuances of what comfort is and can potentially do. To build on these, a new grammar could be developed that is more adequately attuned to narrating corporeal experience. Instead of talking about movement and stillness, we could perhaps think about the relative obduracy or susceptibilities of bodies for feeling different sensations relative to proximate environments. Indeed, even when bodies are relatively still, the perception of proximate spatiality may be pressing or expansive, "constantly in traffic... both multiple and moving" (Honkasalo, 1998, page 36). The nearness and farness of this relation between seat and body, world and self, are constantly renegotiated. The body is pressed up against and hugged by the seat, whilst at the same time it is distinct from it, such as in the case of a painful leg. As Wylie notes drawing on Deleuze, "self and world overlap and separate in a ductile and incessant enfolding and unfolding” (2005, page 240).

Finally, this paper has demonstrated the necessity to take seriously the complexities of corporeal intensity. Where physical comfort may be characterised as a potentially neutral intensity, intensity may take multiple different forms: from the painful physical intensity of an uncomfortable leg to the desirable but perhaps equally powerful intensity of imaginative daydreaming, for example. These intensities are folded through each other and can be mutually supportive or destructive. The physical discomfort of a painful back may be offset by the desirable comfort brought about through absorbing work of imagineering. Such debates clearly feed into relative corporeal absorption whilst being sedentary: how engaged the body is in a particular task. This problematic feeds into further questions of bodily intentionality. Part of the experience of being still may necessarily involve an active performative dimension, of gestures, of engaged activity, and shifts in action as part of performative regimes of resignification. However, such performances which emerge in the course of being sedentary are intersected and are cut across simultaneously by those more-than-agentive sensibilities such as discomfort which emerge and fold through the act of being sedentary. 
We may not always be able to effect comfort. Indeed, for some, sensibilities of comfort may not even be desirable. However, appreciating the complex affectual nature of the sedentary body through the lens of comfort has the effect of constituting multifaceted subjectivities whilst recognising the various corporeal capabilities of affecting and the potentialities to be affected.

Acknowledgements. This paper has benefited hugely not only from the kind and perceptive comments and suggestions of three anonymous referees but also from the countless number of commutes by train made between Newcastle and Durham during the last three years. Additional thanks go to Paul Harrison, Mike Crang, Greg Siegworth, and Rob Loughenbury for extremely useful comment and critique on earlier versions of this paper. Special thanks go to Peter Thomas for inspiration and encouragement. All subsequent omissions and errors remain my own.

\section{References}

Adey P, 2004, "Surveillance at the airport: surveilling mobility/mobilising surveillance" Environment and Planning A $361365-1380$

Adey P, 2007, “'May I have your attention': airport geographies of spectatorship, position, and (im)mobility" Environment and Planning D: Society and Space 25515 -536

Anderson B, 2004, "Time-stilled space-slowed: how boredom matters" Geoforum 35 739-754

Anderson B, 2006, “'Transcending without transcendence': utopianism and an ethos of hope" Antipode $38691-710$

Bachelard G, 1987 On Poetic Imagination and Reverie translated by C Gaudin (Spring Publications, Dallas, TX)

Barthes R, 2005 The Neutral (Columbia University Press, New York)

Bell M, Leong S, 1998 Slowspace (Monacelli Press, New York)

Bennett J, 2001 The Enchantment of Modernity: Crossings, Energetics, and Ethics (Princeton University Press, Princeton, NJ)

Bissell, 2007, "Animating suspension: waiting for mobilities" Mobilities 2 277-298

Buchino J, 2003 Porching: A Humorous Look at America's Favorite Pastime (Minerva, Louisville, KY)

Butler J, 1997 Excitable Speech: A Politics of the Performative (Routledge, London)

Byars M, 2006 New Chairs: Design, Technology and Materials (Laurence King, London)

Callon M, Law J, 2005, "On qualculation, agency, and otherness" Environment and Planning D: Society and Space $23717-733$

Chappell A, 2006, 'Using the 'grieving' process and learning journals to evaluate students' responses to problem-based learning in an undergraduate geography curriculum" Journal of Geography in Higher Education 3015 - 31

Chappells H, Shove E, 2005, "Debating the future of comfort: environmental sustainability, energy consumption and the indoor environment" Building Research and Information 33 32-40

Christiansen K, 1997, "Subjective assessment of sitting comfort" Collegium Antropologicum 21 $387-395$

City Night Line, 2005, "Europe's modern night train”, promotional pamphlet; copy available from author

Cooper G, 1998 Air Conditioning America: Engineers and the Controlled Environment 1990 - 1960 (Johns Hopkins University Press, Baltimore, MD)

Crang M, 1997, "Picturing practices: research through the tourist gaze" Progress in Human Geography $21359-374$

Cranz G, 2000 The Chair: Rethinking Culture, Body and Design (W W Norton, London)

Cresswell T, 2001, "The production of mobilities" New Formations $4312-36$

Cresswell T, 2003, "Introduction: Theorizing place" Thamyris/Intersecting 9 11-32

Cresswell T, 2006, "'You cannot shake that shimmie here': producing mobility on the dancefloor" Cultural Geographies $1355-77$

Cresswell T, Verstraete G (Eds), 2003 Mobilizing Place, Placing Mobility: The Politics of Representation in a Globalized World (Rodopi, Amsterdam)

Crouch D, 2001, "Spatialities and the feeling of doing" Social and Cultural Geography $261-75$

Crowley J, 1999, "The sensibility of comfort" American Historical Review 104 749-782

Crowley J, 2003 The Invention of Comfort: Sensibilities and Design in Early Modern Britain and Early America (Johns Hopkins University Press, Baltimore, MD)

Davis M, 1998 City of Quartz: Excavating the Future in Los Angeles (Pimlico, London)

de Botton A, 2006 The Architecture of Happiness (Hamish Hamilton, London)

de Dampierre F, 2006 Chairs: A History (Harry N Abrams, New York)

Dewsbury J-D, Wylie J, Harrison P, Rose M, 2002, “Enacting geographies” Geoforum 32 437-442 
Duncan J, 1990 The City as Text: The Politics of Landscape Interpretation in the Kandyan Kingdom (Cambridge University Press, Cambridge)

Duncan J, Lambert D, 2004, "Landscapes of home", in A Companion to Cultural Geography Eds J Duncan, N Johnson, R Schein (Blackwell, Oxford) pp 382-403

Evans M, 1980 Housing, Climate, and Comfort (Architectural Press, London)

Fiell C, Fiell P, 20051000 Chairs (Taschen, Köln)

Foucault M, 1991 Discipline and Punish: The Birth of the Prison (Penguin Books, Harmondsworth, Middx)

Gómez F, Tamarit N, Jabaloyes J, 2001, "Green zones, bioclimatics studies and human comfort in the future development of urban planning" Landscape and Urban Planning $55151-161$

Gowans A, 1989 The Comfortable House: North American Suburban Architecture 1890 - 1930 (MIT Press, Cambridge, MA)

Gregson N, Rose G, 2000, "Taking Butler elsewhere: performativities, spatialities and subjectivities" Environment and Planning D: Society and Space 18433 - 452

Greil H, 1997, "Ontogenetic aspects of dimensions and proportions in sitting posture" Collegium Antropologicum $21367-386$

Hannam K, Sheller M, Urry J, 2006, "Editorial: Mobilities, immobilities and moorings" Mobilities $11-22$

Harker C, 2005, "Playing and affective time-spaces" Children's Geographies 3 47-62

Harris T, 1997 The Power of the Porch: Storyteller's Craft in Zora Neale Hurston, Gloria Naylor and Randall Kenan (University of Georgia Press, Atlanta, GA)

Harrison P, 2008, "Corporeal remains: vulnerability, proximity, and living-on after the end of the world" Environment and Planning $A$ (forthcoming)

Helander M, Zhang L, 1997, "Field studies of comfort and discomfort in sitting" Ergonomics 40 $895-915$

Hellstrom C, 2001, "Affecting the future: chronic pain and perceived agency in a clinical setting" Time and Society $1077-92$

Holliday R, 1999, “The comfort of identity” Sexualities 2 475-491

Honkasalo M-L, 1998, "Space and embodied experience: rethinking the body in pain" Body and Society $435-57$

Honkasalo M-L, 2000, "Chronic pain as a posture towards the world" Scandinavian Journal of Psychology 41 197-208

Honkasalo M-L, 2001, "Vicissitudes of pain and suffering: chronic pain and liminality" Medical Anthropology $19319-354$

Hubbard P, 2003, "A good night out? Multiplex cinemas as sites of embodied leisure" Leisure Studies $22255-272$

Jackson J, 1994, "Chronic pain and the tensions between the body as subject and object", in Embodiment and Experience: The Existential Ground of Culture and Self Ed. T J Csordas (Cambridge University Press, Cambridge) pp $201-228$

Jackson J, 2005, "Stigma, liminality, and chronic pain: mind - body borderlands" American Ethnologist 32332 - 353

Larsen J, 2005, "Families seen sightseeing: performativity of tourist photography" Space and Culture 8 416-434

Latham A, Conradson D, 2003, "The possibilities of performance" Environment and Planning A $351901-1906$

Lingis A, 1996 Sensation: Intelligibility in Sensibility (Prometheus Books, New York)

Loori J, 2002 The Art of Just Sitting: Essential Writings on the Zen Practice of Shikantaza (Wisdom Publications, Somerville, MA)

McCaffery M, Wolff M, 1992, "Pain relief using cutaneous modalities, positioning, and movement" Hospital Journal 8121 - 153

McColgan G, 2005, "A place to sit: resistance strategies used to create privacy and home by people with dementia" Journal of Contemporary Ethnography 34410 - 433

McCormack D, 2002, "A paper with an interest in rhythm" Geoforum 33 469-485

McSherry D, 2006, "The budget traveller's guide to sleeping in airports", http://www.sleepinginairports.net/

Malinowski A, Stamler L, 2002, "Comfort: exploration of the concept in nursing” Journal of Advanced Nursing $39599-606$

Massey D, 1993, "Power-geometry and a progressive sense of place", in Mapping the Futures: Local Cultures, Global Change Eds J Bird, B Curtis, T Putnam, G Robertson (Routledge, London) pp 59-69

Mauss M, 1973, "Techniques of the body" Economy and Society $270-88$ 
Meadmore C, 1997 The Modern Chair (Dover, New York)

Merleau-Ponty M, 1962 Phenomenology of Perception (Routledge, London)

Michael M, 2000, "These boots were made for walking ... : mundane technology, the body and human-environment relations" Body and Society 6107 - 126

Miles A, Curran H V, Pearce S, Allan L, 2005, "Managing constraint: the experience of people with chronic pain" Social Science and Medicine 61431 - 441

Morin K, Longhurst R, Johnston L, 2001, “(Troubling) spaces of mountains and men: New Zealand's Mount Cook and Hermitage Lodge" Social and Cultural Geography 2 117-139

Morris B, 2004, "What we talk about when we talk about "walking in the city" Cultural Studies $18675-697$

Nash C, 2000, "Performativity in practice: some recent work in cultural geography" Progress in Human Geography 24653 - 664

Ophir A, 2005 The Order of Evils: Towards an Ontology of Morals (Zone Books, New York)

Parkins W, 2004, "Out of time: fast subjects and slow living" Time and Society 13363 - 382

Powell M, Boyne G, Ashworth R, 2001, "Towards a geography of people poverty and place poverty" Policy and Politics $29243-258$

Sarkar S, 2003, "Qualitative evaluation of comfort needs in urban walkways in major activity centers" Transportation Quarterly 5739 - 59

Scarry E, 1985 The Body in Pain (Oxford University Press, Oxford)

Schrauwers A, 2001, "Sitting in silence: self, emotion, and tradition in the genesis of a charismatic ministry" Ethos $29430-452$

Shove E, 2003a, "Users, technologies and expectations of comfort, cleanliness and convenience" Innovation $16193-206$

Shove E, 2003b, Comfort, Cleanliness and Convenience: The Social Organization of Normality (Berg, Oxford)

Siegworth G, 2000, "Banality for cultural studies" Cultural Studies 14227 - 268

Solnit R, 2000 Wanderlust (Verso, London)

Spark M, 2006, "A neoliberal nexus: economy, security and the biopolitics of citizenship on the border" Political Geography 25151 - 180

Spinney J, 2006, "A place of sense: a kinaesthetic ethnography of cyclists on Mont Ventoux" Environment and Planning D: Society and Space 24 709-732

Stone S, 1995, "The myth of bodily perfection" Disability and Society $10413-424$

Tenner E, 2003 Our Own Devices: The Past and Future of Body Technology (Alfred A Knopf, New York)

Thrift N, 2000, "Afterwords" Environment and Planning D: Society and Space 18 213-255

Thrift N, 2004, "Intensities of feeling: towards a spatial politics of affect" Geografiska Annaler B $8657-78$

Torkelson C, 1999 Get Fit While You Sit: Easy Workouts from Your Chair (Hunter House, Alamdea, CA)

Tuan Y-F, 1975, "Place: an experiential perspective" Geographical Review 65151 - 165

Tutton E, Seers K, 2003, "An exploration of the concept of comfort" Journal of Clinical Nursing $12689-696$

Valentine G, 1999, "Eating in: home, consumption and identity" Sociological Review 47491 - 523

Vidler A, 2000 Warped Space: Art, Architecture and Anxiety in Modern Culture (MIT Press, Cambridge, MA)

Virgin Trains, 2005a, "Virgin Trains: first class", promotional pamphlet; copy available from the author

Virgin Trains, 2005b, "Voyager: welcome to first class", promotional pamphlet; copy available from the author

Virilio P, 1997 Open Sky (Verso, London)

Wylie J, 2005, "A single day's walking: narrating self and landscape on the South West Coast Path" Transactions of the Institute of British Geographers, New Series $30234-247$

Youdell D, 2005, "Sex - gender - sexuality: how sex, gender and sexuality constellations are constituted in secondary schools" Gender and Education $17249-270$

Yu P, 2003, “'My home, my comfort': an ethnography of the fantasy home comfort” Advances in Consumer Research 31113 - 114 
Conditions of use. This article may be downloaded from the E\&P website for personal research by members of subscribing organisations. This PDF may not be placed on any website (or other online distribution system) without permission of the publisher. 